\title{
Accumulation of factors influencing children's middle ear disease: risk factor modelling on a large population cohort
}

\author{
Kathleen E Bennett, Mark P Haggard
}

\begin{abstract}
Study objectives-Data were analysed from a large national birth cohort to examine cumulative and interactive prediction from various risk factors for childhood middle ear disease, and to resolve conflicting evidence arising from small and incompletely controlled studies. The large sample size permitted appropriate covariate adjustment to give generality, and permit demographic breakdown of the risk factors.
\end{abstract}

Setting-A large multi-purpose longitudinal birth cohort study of all births in the UK in one week in 1970, with multiple questionnaire sweeps.

Participants-Over 13000 children were entered into the original cohort. Data on over 12000 children were available at the five year follow up.

Main outcome measures-For children at 5 years, parent reported data were available on health and social factors including data on two markers for middle ear disease: the occurrence of purulent (nonwax) ear discharge and suspected or confirmed hearing difficulty.

Main results-In those children who had ever had reported hearing difficulty (suspected or confirmed), after control for socioeconomic status, three of the classic factors (male sex, mother's smoking habits since birth, and attending day care) were significantly more frequent. In those who had ever had ear discharge reported, only mother's smoking habit since birth was significantly more frequent. However, it showed an orderly dose response relation. In addition, a derived general child health score was found to be significantly associated with both the middle ear disease markers. Control for this variable in the analysis of those having reported hearing difficulty reduced the effect size of mother's smoking habit, but it remained statistically significant. For reported ear discharge, even after control for the general health score and social index, mother's smoking habits and day care attendance were both significant predictors. Mother's (but not father's) smoking habits and day care attendance were found to be significant risk factors for middle ear disease. Breast feeding effects were weak and did not generally survive statistical control.
Conclusions-A child having all three risk factors (attends day care, a mother who smokes, and male sex) is 3.4 times more likely to have problems with hearing than a child who has none, based on cumulative risk. Further studies should focus on preventative risk modification and well specified intervention.

(F Epidemiol Community Health 1998;52:786-793)

Otitis media with effusion (OME) is the most common cause of hearing impairment in children and the most common reason for surgery in children in most western countries. Approximately $80 \%$ of children have at least one episode of otitis media with effusion before their fourth birthday. ${ }^{1}$ Recently, political debate on rationing of health care has questioned the effectiveness of treatments for OME. The emphasis has moved towards more "watchful waiting" in primary care, but this raises several issues; whether effective alternative management strategies (for example, palliative or preventative approaches to OME such as modification of risk factors by parents with otitis prone children" are possible); whether "watchful waiting" can really be defined as more than benign neglect; and whether classic or newly established risk factors could select cases more appropriately for treatment without delay.

\section{Overview}

Of over 30 risk factors reported more than once in the literature, only a handful are replicated in virtually all the adequate studies addressing them, and the cumulative effect of these factors tends not to be very large. Many studies in the literature consider risk factors related to episode incidence or to point prevalence of OME. ${ }^{3}$ Few studies have specifically considered recurrence/persistence, ${ }^{4}$ which is more closely related to clinical and parental concern. The most consistently found risk factor is day care setting ${ }^{45}$ but it is unlikely that parents' economic circumstances and the other social benefits from day care will permit a disease not perceived as serious to determine attendance. Two other risk factors that feature frequently are passive smoking ${ }^{6-9}$ and bottle versus breast feeding. ${ }^{310}$ However, these factors are not beyond controversy and require detailed dose response relations to be replicated. Season, allergy, ${ }^{11} \operatorname{sex}^{3}$ and race have emerged in more than one study, but unlike the preceding two are not amenable to intervention. There is a long list of further possible factors noted in scattered studies and reviews. ${ }^{3}{ }^{12-14}$ 
Unless these factors have a strong pathogenetic rationale, high prevalence or obvious clinical relevance, the resources are unlikely to be found to organise studies that overcome the problems of low statistical power and discrepant results in such a way as to underpin risk factor determination as a basis of practice.

\section{Reported data}

In children's middle ear disease, the term "history" has two main connotations: what is reported (awareness) as distinct from examination, and the cumulative record of episodes, signs, and symptoms. The connection is not arbitrary-it is impractical to observe or measure repeatedly over a long period. As the literature suggest a great overlap of proneness and risk factors for the related conditions of recurrent acute otitis media (RAOM) and OME, we use the term middle ear disease (MED) here to avoid the implications of an AOM-OME diagnostic distinction that is increasingly hard to sustain in terms of history or impact. ${ }^{10}$ There is good theoretical and epidemiological reason to regard persistence as the main basis for concern in $\mathrm{OME}^{15}$ but only in prospective longitudinal studies can this be established by repeated objective measurements. Parental report, therefore, has to suffice for many purposes, requiring in turn knowledge of its limitations to allow cautious interpretation. Given the fluctuations in OME over time, the integration of parental judgements over time, and the selectivity for more severe histories exercised by memory, parent report data may be worth more than the objectivity of isolated measurements. It must, however, be noted that report will be under-sensitive to mild/short histories, and many parents will be less sensitive to the behavioural signs than organic symptoms. Few studies have considered the accuracy of parental reporting of children's disease history. Those that have ${ }^{16} 17$ show that parental reporting (particularly mothers and parents of younger aged children) can be fairly accurate when compared with medical records, although further studies are desirable. In practical terms influences on report from chronicity, duration of recall, and seriousness of the event, may in the context of a mild self limiting condition such as OME even be an advantage.

\section{Statistical power and multiple risk factor models}

For clinical targeting and for control in intervention research, the development of an aggregate risk score is desirable; this can include report data and is accepted as a prime basis of stratification in research and treatment in the cardiovascular field. ${ }^{18}$ Many previous risk factor studies in otitis media have used only univariate analyses, hence lacking control for confounders and saying nothing about accumulation or interactions among several factors acting simultaneously.

Conflicting results between various risk factor studies may reflect population differences, but are more likely to reflect differing recruitment biases, poor control for confounders, sampling fluctuations, effects that are marginal overall, and the studies' low statistical power. For example, in the literature on passive smoking in otitis media, the number of papers showing some association is almost equalled by that showing no association. ${ }^{19}$ The better designed large studies do show an association. ${ }^{7}$ In view of the need to base health promotion advice about smoking or breast feeding on the widest range of verified harmful effects that may activate individuals' concerns, it is necessary to use very large datasets to achieve stable statistical correction for several possible confounders.

To quantify magnitudes of effect, any interactions and the combined predictive value of the classic triad of risk factors in middle ear disease, we have analysed data from a national birth cohort of over 12000 children. We have produced an optimal risk factor model of the data, controlling background variables such as socioeconomic group, non-specific general health, and other ENT disease. On such numbers, repeated objective measurements are impractical, therefore integrative report by parents of significant histories up to age 5 has been used. One aim of the present analyses was to establish consistency or otherwise of risk factors for middle ear disease found in other studies using different disease markers.

\section{Methods}

SAMPLE AND DEPENDENT VARIABLES

The UK 1970 national birth cohort collected data on children from birth to 21 years by intermittent sweeps; more detail on the cohort is given elsewhere. ${ }^{20}$ At age 5 questionnaires on the child's medical and social background were completed by the mother on some 13135 children. For analysis purposes, the total numbers included ranged from around 9000 to 11000 depending on the availability of items. Two markers for middle ear disease were reported: whether or not the child had "suspected or confirmed hearing difficulty" up to the age of 4 , and similarly between 4 and 5; and whether or not there had been any "purulent (that is, nonwax) ear discharge" in the same age periods. A third derived dichotomous variable was used to describe those children having no reported ear discharge or hearing difficulty, compared with those having both ear discharge and hearing difficulty (that is, the $3 \%$ probably "most severe"). The very few cases $(n=23)$ of permanent hearing impairment were excluded from analysis.

\section{CONTROL VARIABLES}

Univariate contingency analyses of the ear discharge and hearing difficulty variables with some of the known risk factors have been presented elsewhere. ${ }^{20}$ Table 1 shows the univariate analyses of the conjoint hearing variable. As a behavioural variable, reported hearing problem displays a social trend in the reporting threshold (more reports in the more advantaged socioeconomic groups, the reverse of the social trend for expected prevalence); the possible differential (mis)classification of disease status will affect the odds ratios and although adjustment is made for this in the analysis it may not remove all the effects of reporting (or 
recall) bias. Multiple logistic regression was performed on each of the two middle ear disease markers, allowing odds ratios and corresponding $95 \%$ confidence intervals to be computed. These regressions were subject to covariate adjustment according to social index (a variable derived from seven socioeconomic data items, ${ }^{21}$ including father's occupation, highest qualification, neighbourhood, housing tenure, etc). There was no attrition bias with respect to social index. This index is an important covariate and helps to eliminate confounding, particularly for reported hearing difficulty.

Non-specific ENT disease and the child's general health score were controlled for to compensate for the partly subjective character of the markers of middle ear disease. These were: (a) whether or not there had been any "mouth-breathing or habitual snoring" (partly related to non-specific ENT disease), and (b) a measure of the child's family's tendency to take up services and recall episodes reflecting general health at the time. For the latter, six individual health items were summed from the questionnaire (only a limited number of health items were available for the cohort at 5 years), categorised as to presence or absence. The items were: ever having had pneumonia, meningitis, eczema, hayfever/sneezing, a hernia operation or an appendicectomy. Health items relating to ENT specific disease, for example, respiratory tract infection were excluded from this child health score, as these are known to be highly correlated with the middle ear disease markers being studied. The health score was significantly associated both with ever having had ear discharge and hearing difficulty up to age 5. Control for mouth breathing was introduced as this is known to be associated with middle ear disease. Control for the child's general health provides control for a mixture of actual health status, service uptake and parental reporting bias and generally increases the assurance that associations result specifically from middle ear disease. A standard trio of analyses was performed, correcting for neither of these covariates, then each separately.

Adjustments for these covariates render the analyses conservative in respect of risk factors for ear disease. "Over-correction" will generally arise when more than one of these related factors is used to correct estimates and will tend to lead to a reduction in the true effect, which is why each was considered separately.

\section{INDEPENDENT VARIABLES}

Social and health items from the questionnaires that were considered potential risk factors for middle ear disease were identified as independent variables. Issues of reporting bias and measurement error, particularly for items such as maternal smoking habits or breast feeding, apply for the independent variables as they do for the dependent variables. Variables included in the logistic models for each middle ear disease marker were (a) sex, (b) day care, (c) duration of breast feeding (never, <1 month, 1-3 months, and >3 months), (d) maternal/paternal smoking habits (dichotomised into ever/ never having smoked during the last 5 years), (e) mother smoking during pregnancy (dichotomised into not smoking and smoking some/all of the time during pregnancy), (f) birth weight ( $<5 \mathrm{lb}, 5-9 \mathrm{lb},>9 \mathrm{lb})$, and $(\mathrm{g})$ mother's age at the time of birth. Day care (b) was categorised into non-attendance, those who attended the local education authority run nursery and "infant" (reception class in primary school) schools, and those attending privately run nursery and infant schools. As the available report of current day care attendance does not take into account day care attendance in early life, early exposure to infection may be underestimated in the analyses.

MODELLING STRATEGY

Variables at a value $\alpha=0.05$ were included in a multiple logistic regression model using GLIM $^{22}$ in forward stepwise selection, on each of the binary dependent variables (reported ear discharge, hearing difficulty or having both problems). Interactions (multiplicative) were considered in all regression analyses. Odds ratios are presented with $95 \%$ confidence intervals. Cumulative odds ratios that represent the cumulative risk of having all significant risk factors compared with having none are also given.

\section{Results}

Preliminary analyses suggested little difference between the reported rates of ear discharge and hearing difficulty in the two periods (up to age 4 and between 4 and 5), although we might have expected higher rates in the younger age group. Data in the two age categories were therefore combined to derive dependent variables relating to ever or never having reported ear discharge or hearing difficulty up to age 5 . Results from using the "suspected or confirmed hearing difficulty" variable therefore reflect cumulative OME severity and persistence. For reported ear discharge, an organic variable, no trend is observed across socioeconomic status. This variable may well reflect net severity of recurrent acute otitis media. The association between the two middle ear disease markers in the study is strong (odds ratio of 4.76), showing sufficient reliability and validity to justify proceeding to risk factor analyses.

Table 1 displays the percentage of children with reported ear discharge or hearing difficulty up to age 5, according to the main independent variables along with univariate $\chi^{2}$ and $\mathrm{p}$ values.

\section{EAR DISCHARGE}

There were significant univariate risk effects on ear discharge from sex, mother's smoking habits and smoking habits during pregnancy, number of household moves and tenure of accommodation. In the multiple logistic regression model, without control for the above covariates, maternal smoking, sex, and day care were all significantly associated with ear discharge, giving a cumulative odds ratio of 2.4.

In the logistic model controlling for social status and non-specific ENT disease, 10710 cases were included (table 2(A)). Only mother's smoking habit remained significant. The 
Table 1 Percentages of children at 5 years with ear/hearing problems by social and health factors

\begin{tabular}{|c|c|c|c|c|c|c|}
\hline Variable & $\begin{array}{l}\% \text { With ear } \\
\text { discharge }\end{array}$ & $\begin{array}{l}p \text { value } \\
\left(\chi^{2}\right)\end{array}$ & $\begin{array}{l}\% \text { With hearing } \\
\text { difficulty }\end{array}$ & $\begin{array}{l}p \text { value } \\
\left(\chi^{2}\right)\end{array}$ & $\begin{array}{l}\% \text { With both } \\
\text { problems }\end{array}$ & $\begin{array}{l}p \text { value } \\
\left(\chi^{2}\right)\end{array}$ \\
\hline \multicolumn{7}{|l|}{ Sex } \\
\hline Male & 12.1 & \multirow[t]{2}{*}{0.034} & 9.3 & \multirow{2}{*}{0.000} & 3.3 & \multirow{2}{*}{0.070} \\
\hline Female & 10.9 & & 7.4 & & 2.7 & \\
\hline \multicolumn{7}{|l|}{ Duration of breast feeding ${ }^{\star}$} \\
\hline Never & 11.9 & \multirow{4}{*}{0.391} & 7.8 & \multirow{4}{*}{0.009} & 3.0 & \multirow[t]{4}{*}{0.374} \\
\hline$<1$ month & 10.6 & & 9.5 & & 2.7 & \\
\hline $1-3$ months & 10.1 & & 8.4 & & 2.4 & \\
\hline$>3$ months & 12.1 & & 10.1 & & 4.0 & \\
\hline \multicolumn{7}{|l|}{ Present placement } \\
\hline Doesn't attend & 9.3 & \multirow[t]{3}{*}{0.191} & 4.3 & \multirow[t]{3}{*}{0.000} & 1.1 & \multirow[t]{3}{*}{0.018} \\
\hline State school & 11.7 & & 8.6 & & 3.2 & \\
\hline Private school & 12.3 & & 10.1 & & 3.8 & \\
\hline \multicolumn{7}{|l|}{ Smoking habits mother since } \\
\hline $1970^{\star}$ & & & & & & \\
\hline Doesn't & 10.1 & \multirow{5}{*}{0.000} & 7.8 & 0.134 & 2.4 & 0.001 \\
\hline$<1$ year & 14.7 & & 12.4 & & 3.4 & \\
\hline $1-3$ years & 13.3 & & 10.0 & & 4.0 & \\
\hline$>3$ years & 13.2 & & 10.1 & & 4.4 & \\
\hline All time & 12.8 & & 8.5 & & 3.6 & \\
\hline Smoking habits father since & & & & & & \\
\hline $1970^{\star}$ & & & & & & \\
\hline Doesn't & 10.4 & 0.06 & 8.8 & 0.197 & 3.0 & 1.0 \\
\hline$<1$ year & 13.5 & & 7.8 & & 3.5 & \\
\hline $1-3$ years & 11.3 & & 9.9 & & 3.4 & \\
\hline$>3$ years & 12.2 & & 10.0 & & 3.5 & \\
\hline All time & 11.8 & & 7.9 & & 3.0 & \\
\hline $\begin{array}{l}\text { Mother's smoking habits dur } \\
\text { pregnancy }\end{array}$ & & & & & & \\
\hline Doesn't smoke & 1.01 & 0.000 & 7.8 & 0.110 & 2.4 & 0.001 \\
\hline Stopped before & 11.1 & & 8.8 & & 2.8 & \\
\hline Stopped during & 12.1 & & 9.5 & & 2.9 & \\
\hline $\begin{array}{l}\text { Continued smoking 1-14 } \\
\text { cigs/day }\end{array}$ & 13.0 & & 8.6 & & 3.8 & \\
\hline $\begin{array}{l}\text { Continued smoking } \geqslant 15 \\
\text { cigs/day }\end{array}$ & 13.0 & & 8.8 & & 3.5 & \\
\hline $\begin{array}{l}\text { Number of cigarettes smoke } \\
\text { mother (per day) }\end{array}$ & & & & & & \\
\hline None & 10.5 & 0.000 & 8.0 & 0.025 & 2.4 & 0.000 \\
\hline $1-14$ & 11.6 & & 8.4 & & 3.5 & \\
\hline 15 or more & 14.1 & & 9.3 & & 4.5 & \\
\hline $\begin{array}{l}\text { Number of cigarettes smoke } \\
\text { father (per day) }{ }^{\star}\end{array}$ & & & & & & \\
\hline None & 11.6 & 0.586 & 8.3 & 0.040 & 3.1 & 0.636 \\
\hline $1-14$ & 10.0 & & 8.0 & & 2.5 & \\
\hline 15 or more & 12.1 & & 7.7 & & 3.0 & \\
\hline Social index ${ }^{\star}$ & & & & & & \\
\hline 1 (most advantageous) & 11.8 & 0.370 & 11.3 & 0.000 & 3.8 & 0.013 \\
\hline 2 & 11.6 & & 10.6 & & 3.8 & \\
\hline 3 & 11.4 & & 9.4 & & 3.4 & \\
\hline 4 & 10.2 & & 7.5 & & 2.1 & \\
\hline 5 & 11.2 & & 7.6 & & 2.6 & \\
\hline 6 & 12.5 & & 7.3 & & 3.3 & \\
\hline 7 (most disadvantageous) & 12.4 & & 5.8 & & 2.9 & \\
\hline Birth weight & & & & & & \\
\hline$<5 \mathrm{lbs}$ & 13.1 & 0.312 & 7.7 & 0.687 & 3.1 & 0.948 \\
\hline $5.5-9 \mathrm{lbs}$ & 11.5 & & 8.5 & & 3.1 & \\
\hline$>9 \mathrm{lbs}$ & 10.9 & & 8.1 & & 3.0 & \\
\hline Mother's age & & & & & & \\
\hline$<35$ & 11.5 & 0.715 & 8.6 & 0.049 & 3.1 & 0.338 \\
\hline$\geqslant 35$ & 12.0 & & 6.8 & & 2.5 & \\
\hline Number of household moves & & & & & & \\
\hline$<3$ & 11.3 & 0.002 & 8.1 & 0.003 & 2.9 & 0.003 \\
\hline$\geqslant 3$ & 13.9 & & 10.4 & & 4.4 & \\
\hline Tenure & & & & & & \\
\hline Owned/being bought & 10.8 & 0.023 & 8.9 & 0.021 & 2.9 & 0.330 \\
\hline Public rent & 12.4 & & 7.3 & & 3.0 & \\
\hline Private rent & 12.1 & & 8.2 & & 3.7 & \\
\hline Other & 14.1 & & 9.3 & & 4.2 & \\
\hline
\end{tabular}

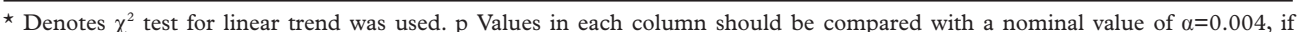
Bonferroni correction is applied.

dose response relation between maternal smoking and reported ear discharge is shown in table 1, where there is a statistical significant linear trend in the reported ear discharge the number of cigarettes smoked by the mother. This relation implicates maternal smoking as a causal risk factor for ever having ear discharge, independent of social index. Children whose mothers smoked were at a $30 \%$ increased risk of ever having purulent ear discharge before 5 years of age. After inclusion of mother's smoking habits, none of the remaining independent variables were significant. Mother's smoking during pregnancy and father's smoking habits at 5 years are highly associated with mother's smoking habits at 5 years. Multicollinearity explains why these effects do not appear in the regression model. Current maternal smoking will be more highly associated with actual exposure than either of the other two smoking measures collected but some causal role for them cannot be ruled out. Male sex, day care, breast feeding, birth weight, number of household moves, tenure of housing, and overcrowding did not significantly affect the risk of having ear discharge. 
Table 2(A) Logistic regression model for purulent (non-wax) ear discharge: significant main effects and unadjusted and adjusted ${ }^{\star}$ odds ratios

\begin{tabular}{|c|c|c|c|c|}
\hline \multirow[b]{2}{*}{ Effect } & \multicolumn{2}{|l|}{ Odds ratio } & \multirow{2}{*}{$\begin{array}{l}95 \% \\
\text { Confidence intervals } \\
\text { for adjusted OR }\end{array}$} & \multirow[b]{2}{*}{$p$ Value } \\
\hline & Unadjusted & Adjusted $^{\star}$ & & \\
\hline \multicolumn{5}{|l|}{ Mother's smoking habits } \\
\hline Does not smoke & 1.0 & 1.00 & & \\
\hline Does smoke & 1.34 & 1.28 & (1.13 to 1.45$)$ & 0.000 \\
\hline \multicolumn{5}{|l|}{ Sex } \\
\hline Female & 1.0 & 1.0 & & \\
\hline Male & 1.12 & 1.10 & (0.97 to 1.24$)$ & 0.123 \\
\hline \multicolumn{5}{|l|}{ Day care } \\
\hline Does not attend & 1.0 & 1.0 & & \\
\hline Attends State school & 1.46 & 1.44 & (1.04 to 2.01$)$ & \\
\hline Attends Private school & 1.59 & 1.55 & (1.06 to 2.28$)$ & 0.071 \\
\hline
\end{tabular}

*Adjusted for social index and mouth breathing/snoring; $\mathrm{n}=10710$.

The next logistic regression model considered as a covariate the highly significant derived general health score $(\mathrm{p}<0.01,10862$ cases ). After controlling for the child's general health score and social index, two factors were found to be significant predictors of having reported ear discharge at 5 years: mother's smoking habits and attending day care. Table 3 (A) gives odds ratios and confidence intervals for these main effects, with odds of between 1.4 to 1.5 of attending day care and having reported ear discharge-that is, over a $40 \%$ increased risk of ear discharge with attendance at day care.

HEARING DIFFICULTY

There were significant univariate effects on "suspected/confirmed hearing difficulty" of male sex, duration of breast feeding, attending day care, smoking habits of the mother (when dichotomised into "ever" or "never" smoked), social index, mother's age at birth of the child,

Table 2(B) Logistic regression model for suspected/confirmed hearing difficulty: significant main effects and unadjusted and adjusted ${ }^{\star}$ odds ratios

\begin{tabular}{|c|c|c|c|c|}
\hline \multirow[b]{2}{*}{ Effect } & \multicolumn{2}{|l|}{ Odds ratio } & \multirow{2}{*}{$\begin{array}{l}95 \% \\
\text { Confidence intervals } \\
\text { for adjusted OR }\end{array}$} & \multirow[b]{2}{*}{$p$ Value } \\
\hline & Unadjusted & Adjusted ${ }^{\star}$ & & \\
\hline \multicolumn{5}{|l|}{ Sex } \\
\hline Female & 1.0 & 1.00 & & \\
\hline Male & 1.29 & 1.26 & (1.10 to 1.45$)$ & 0.001 \\
\hline \multicolumn{5}{|l|}{ Mother's smoking habits } \\
\hline Does not smoke & 1.0 & 1.00 & & \\
\hline Does smoke & 1.22 & 1.31 & (1.14 to 1.51$)$ & 0.000 \\
\hline \multicolumn{5}{|l|}{ Day care } \\
\hline Does not attend & 1.0 & 1.00 & & \\
\hline Attends State school & 2.24 & 1.78 & (1.15 to 2.77$)$ & 0.010 \\
\hline Attends Private school & 2.83 & 2.04 & $(1.25$ to 3.32$)$ & \\
\hline $\begin{array}{l}\text { Cumulative risk of having all three } \\
\text { risk factors }\end{array}$ & 4.44 & 3.37 & $(1.99$ to 5.71$)$ & \\
\hline
\end{tabular}

* Adjusted for social index and mouth breathing/snoring; $\mathrm{n}=10880$.

Table 2(C) Logistic regression model for conjoint ear/hearing variable: significant main effects and unadjusted and adjusted ${ }^{\star}$ odds ratios

\begin{tabular}{|c|c|c|c|c|}
\hline \multirow[b]{2}{*}{ Effect } & \multicolumn{2}{|l|}{ Odds ratio } & \multirow{2}{*}{$\begin{array}{l}95 \% \\
\text { Confidence intervals } \\
\text { for adjusted OR }\end{array}$} & \multirow[b]{2}{*}{$p$ Value } \\
\hline & Unadjusted & Adjusted $^{\star}$ & & \\
\hline \multicolumn{5}{|l|}{ Mother's smoking habits } \\
\hline Does not smoke & 1.0 & 1.00 & & \\
\hline Does smoke & 1.56 & 1.51 & (1.17 to 1.95$)$ & 0.002 \\
\hline \multicolumn{5}{|l|}{ Sex } \\
\hline Female & 1.0 & 1.0 & & \\
\hline Male & 1.24 & 1.23 & (0.97 to 1.57$)$ & 0.096 \\
\hline \multicolumn{5}{|l|}{ Day care } \\
\hline Does not attend & 1.0 & 1.0 & & \\
\hline Attends State school & 3.10 & 2.56 & $(1.04$ to 6.29$)$ & \\
\hline Attends Private school & 4.13 & 3.05 & (1.15 to 8.06$)$ & 0.090 \\
\hline
\end{tabular}

* Adjusted for social index and mouth breathing/snoring; $n=9513$.
KEY POINTS

- The three main risk factors predicting reported hearing difficulty up to age 5 are maternal smoking, day care attendance, and male sex.

- A child having all three of these risk factors is 3.4 times more likely to have problems with hearing than a child who has none.

- This large study calls into question the importance of breast feeding as a protective factor in middle ear disease.

number of household moves, and tenure of accommodation.

In a multiple logistic regression model without control for the standard covariates, the factors significantly associated with hearing difficulty were sex, maternal smoking and day care, giving a cumulative odds ratio of 4.44 .

In the logistic regression model for hearing difficulty (on 10880 cases, see table 2(B)), male sex, attending day care, and mother's smoking habits were significant. The risk of reported hearing difficulty in children attending day care was almost twice that in children not attending. The risk of reported hearing difficulties was $26 \%$ higher in boys compared with girls. Children whose mothers smoked were at a 30\% increased risk (comparable to the effect observed on ear discharge). Duration of breast feeding, birth weight, number of household moves, housing tenure, and overcrowding did not contribute significantly to the regression model for reported hearing difficulty.

The alternative logistic regression model including the significantly associated child general health score and social index (on 10859 cases) confirmed male sex, mother's smoking habits, and attending day care as significant factors in hearing difficulty at age 5 (see table 3 (B)). The effect of mother's smoking habits was slightly increased when adjusting for the general health score (from an odds ratio of 1.22 to 1.26 ), because of the negative association between these two variables.

Smoking during pregnancy was not significant when all other factors were taken into account. Table 1 shows the number of cigarettes smoked per day by the mother and the father by the percentage of children ever having ear/hearing problems. For both, the risk increases with increased number of cigarettes smoked, underlining the result for ear discharge with maternal dose as pointer to causality.

DERIVED MIDDLE EAR DISEASE VARIABLE (CONJUNCTION OF THE TWO MIDDLE EAR DISEASE MARKERS)

There were significant univariate effects of mothers smoking habits, number of household moves, and day care attendance.

In the multiple logistic regression without covariate adjustment, sex, maternal smoking, and day care were all significantly associated with having both ear discharge and hearing difficulty, giving a cumulative odds ratio of 8.2. 
Table 3(A) Logistic regression model for purulent (non-wax) ear discharge: significant main effects and unadjusted and adjusted ${ }^{\star}$ odds ratios

\begin{tabular}{|c|c|c|c|c|}
\hline \multirow[b]{2}{*}{ Effect } & \multicolumn{2}{|l|}{ Odds ratio } & \multirow{2}{*}{$\begin{array}{l}95 \% \\
\text { Confidence intervals } \\
\text { for adjusted OR }\end{array}$} & \multirow[b]{2}{*}{ p Value } \\
\hline & Unadjusted & Adjusted $^{\star}$ & & \\
\hline \multicolumn{5}{|l|}{ Mother's smoking habits } \\
\hline Does not smoke & 1.00 & 1.00 & & \\
\hline Does smoke & 1.35 & 1.31 & (1.16 to 1.49$)$ & 0.000 \\
\hline \multicolumn{5}{|l|}{ Day care } \\
\hline Does not attend & 1.00 & 1.00 & & \\
\hline Attends State school & 1.46 & 1.41 & (0.96 to 2.06$)$ & \\
\hline Attends Private school & 1.59 & 1.49 & (1.07 to 2.09$)$ & 0.048 \\
\hline $\begin{array}{l}\text { Cumulative risk of having all two risk } \\
\text { factors }\end{array}$ & & 1.95 & (1.79 to 2.13$)$ & \\
\hline
\end{tabular}

^ Adjusted for social index and child health score; $\mathrm{n}=10862$.

Table 3(B) Logistic regression model for suspected/confirmed hearing difficulty: significant main effects and unadjusted and adjusted ${ }^{\star}$ odds ratios

\begin{tabular}{|c|c|c|c|c|}
\hline \multirow[b]{2}{*}{ Effect } & \multicolumn{2}{|l|}{ Odds ratio } & \multirow{2}{*}{$\begin{array}{l}95 \% \\
\text { Confidence intervals } \\
\text { for adjusted OR }\end{array}$} & \multirow[b]{2}{*}{$p$ Value } \\
\hline & Unadjusted & Adjusted $^{\star}$ & & \\
\hline \multicolumn{5}{|l|}{ Sex } \\
\hline Female & 1.00 & 1.00 & & \\
\hline Male & 1.29 & 1.29 & (1.12 to 1.50$)$ & 0.000 \\
\hline \multicolumn{5}{|l|}{ Mother's smoking habits } \\
\hline Does not smoke & 1.00 & 1.00 & & \\
\hline Does smoke & 1.22 & 1.26 & (1.09 to 1.46$)$ & 0.002 \\
\hline \multicolumn{5}{|l|}{ Day care } \\
\hline Does not attend & 1.00 & 1.00 & & \\
\hline Attends State school & 2.24 & 1.77 & (1.05 to 2.98$)$ & \\
\hline Attends Private school & 2.83 & 1.97 & (1.22 to 3.18$)$ & 0.009 \\
\hline $\begin{array}{l}\text { Cumulative risk of having all three } \\
\text { risk factors }\end{array}$ & & 3.2 & (1.82 to 5.62$)$ & \\
\hline
\end{tabular}

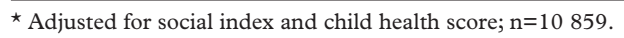

Table 3(C) Logistic regression model for conjoint hearing difficulty/ear discharge: significant main effects and unadjusted and adjusted ${ }^{\star}$ odds ratios

\begin{tabular}{|c|c|c|c|c|}
\hline \multirow[b]{2}{*}{ Effect } & \multicolumn{2}{|l|}{ Odds ratio } & \multirow{2}{*}{$\begin{array}{l}95 \% \\
\text { Confidence intervals } \\
\text { for adjusted OR }\end{array}$} & \multirow[b]{2}{*}{ p Value } \\
\hline & Unadjusted & Adjusted ${ }^{\star}$ & & \\
\hline \multicolumn{5}{|l|}{ Sex } \\
\hline Female & 1.00 & 1.00 & & \\
\hline Male & 1.22 & 1.43 & (1.09 to 1.87$)$ & 0.014 \\
\hline \multicolumn{5}{|l|}{ Mother's smoking habits } \\
\hline Does not smoke & 1.00 & 1.00 & & \\
\hline Does smoke & 1.56 & 1.60 & (1.21 to 2.11$)$ & 0.000 \\
\hline \multicolumn{5}{|c|}{ Cumulative risk of having all two risk } \\
\hline factors & 1.90 & 2.29 & (1.51 to 3.14$)$ & \\
\hline
\end{tabular}

^ Adjusted for social index and child health score; $\mathrm{n}=9354$.

In a logistic regression controlling for social index and snoring/mouth breathing (both highly significant in this analysis), 9513 cases were included. Only mothers' smoking habits remained significant. Children whose mothers smoked were at a $51 \%$ increased risk of ever having both ear discharge and hearing difficulty up to age 5 . Table 2 (C) gives the odds ratio and $95 \%$ confidence intervals for maternal smoking habits.

The logistic regression model including the derived general health score together with social index, and the above risk factors found two significant factors: sex and mothers' smoking habits (table 3 (C) gives odds ratios and confidence intervals). Although the odds ratio associated with attending day care and having both problems was large (approximately 3.0), the overall effect of attending day care was on the margin of significance $(p=0.08)$ because of the small numbers involved ( $n=5$ in the smallest cell). Broadly, the combined variable shows stronger effects as expected.

In each regression model, for all three dependent variables, interactions between risk factor variables were considered but none were found to be significant ( $p>0.05)$.

\section{Discussion}

INTERPRETATION OF THE MARKERS

The two disease markers used are associated, and strong conclusions are possible where trends for the two markers agree. True trends may emerge strongly for the conjunction of the two markers, as witnessed by the magnitude (in ratio terms) of the dose response effect for maternal smoking in table 1 . We have shown that, on a univariate basis, the reported markers do replicate the classic otitis media risk factors overall. The main difference between the models is for sex, not appearing in the ear discharge model, but this is also a less prominent risk factor for acute otitis media. Parental reporting is the only feasible marker for a very large sample, and the univariate results we obtain agree well with results based on more objective measurement.

The two markers also produce absolute prevalence rates in the right range for a degree of history justifying concern (8-12\%) and corresponding with surgical intervention levels in the UK $(3-4 \%)$. The present analysis has the strength of being broadly generalisable because of its population-based design, of controlling for influential factors such as socioeconomic status in a multivariate regression model, of providing cumulative effects of risk factors, and examining interactions often ignored in risk factor studies; it thus complements smaller studies having more objective diagnostic markers but which lack these other virtues.

Studies examining parental reporting ${ }^{16} 17$ show an adequate association with data collected via medical records, although it depends to some degree on the severity of the condition and length of recall of the parent. A parental report of ear discharge is presumably based upon on the severity of acute otitis media. Reports of hearing difficulty are presumably based more on OME. However in a child's overall history, as distinct from a particular day, the diagnostic distinction is only approximately valid. Risk factors for acute otitis media and $\mathrm{OME}$ are virtually identical and this is reflected here with similar risk factor models for ear discharge and hearing difficulty. The absence of interactions in our analyses suggests that risk factors (environmental or otherwise) for middle ear disease act independently.

PASSIVE SMOKING

Of the risk factors studied, mothers' but not fathers' smoking habits appear an important factor in the presence or otherwise of ear/ hearing problems of 5 year olds. This could arise in two ways: because the mother is more likely to spend time with the child and, if she smokes, the child is more likely to be exposed to the tobacco smoke, or because there may be some damaging effects to the immune system in utero. Although smoking during pregnancy showed a significant dose response relation for the child having ear discharge at 5 years, it was prevented from entering into the model because of the inter-relation with reporting of 
smoking since birth (in both parents). Mothers who smoked during pregnancy tend to be the same mothers who continue after pregnancy (correlation $r=0.83, \mathrm{p}<0.001$ ), and because of the strong association between these measures only one will appear in the regression model. Others, ${ }^{23}$ using this same dataset, have shown that children of mothers who gave up during pregnancy were at a lower risk of disease than those continuing, who tended to be the same mothers smoking after pregnancy. From those analyses it could not be established in which trimester smoking was having the greatest effect. The strong emergence of smoking in this very large study adds considerably to the positive evidence for passive smoking as a risk factor in middle ear disease. A recent small study in family practice, ${ }^{14}$ found the opposite pattern: no smoking effect, but did find a breast feeding effect. This may have been because of low power and lack of multivariate adjustment especially for socioeconomic status, rather than to any changes in practice over the decades and recommendation from that work should not be based on its apparent population generality because it was based in family practice.

Parental smoking has a generally negative effect on child health. ${ }^{24}$ Cotinine concentration values as a marker used in some studies ${ }^{67}$ are a more precise measure of exposure to environmental tobacco smoke and have shown dose response effects. The sample size underlying our results strengthen the recommendation that smoking in the presence of a child should be reduced or removed to decrease the risk of the child having MED among other health problems.

DAY CARE

The second classic risk factor to show an association here with middle ear disease was the child's current school placement at age 5 . The odds ratio showed an almost doubling of risk of hearing difficulty, and a tripling of risk of having both problems, in children who attend some type of day care compared with those who do not. This is confirmatory of other studies, ${ }^{35}$ and is probably because of the increased risk of exposure to pathogens in a school environment, compared with staying at home. The apparently raised prevalence in private reception classes of primary schools (but not in nursery schools) is paradoxical, and may include some reporting bias related to socioeconomic status. Further investigations on increased risk in day care centres should focus on preventative risk modification or intervention. Others have concluded $^{25}$ that more frequent handwashing among staff and pupils and semi-isolation of children with upper respiratory tract infection in day care could contribute to the reduction in incidence of upper respiratory tract infection and subsequent AOM.

SEX

There is a small but consistent difference in cumulative incidence and prevalence of OME and $\mathrm{AOM}$ in males compared with females. ${ }^{10}$ Although some studies do not show an effect of sex, ${ }^{3}$ it occurs widely in epidemiological data on both AOM and OME. The effect on reported hearing difficulty in a large population of 5 year olds is probably because of the same underlying predisposition. The odds ratios are too low to consider sex as any basis for at risk screening, and within a more reactive surveillance system it would probably be inefficient to override data from other observations by using gender data when considering investigation and referral.

BREAST FEEDING

Breast feeding could be more closely associated with reduced OME (immune reaction) than with reduced AOM (occurrence of infection as possibly described by ear discharge). For hearing difficulty, one reason for the relative weakness here of breast feeding (that is, not entering the multivariate model) may relate to social stratification. Breast feeding was and remains more common in higher socioeconomic groups; two effects may be working in opposition, a lower prevalence of MED, but a higher prevalence of breast feeding and otitis media reporting in more fortunate families.

The paradoxical direction of the breast feeding effect for reported hearing difficulty shown here may reflect over-correction, and underlines the need for carefully controlled and interpreted multivariate analyses, and a good broadly based measure of socioeconomic status. Some studies have shown a protective effect of breast feeding ${ }^{1026-28}$ after control for factors such as size of family, smoking and socioeconomic group or parental education (as a marker for socioeconomic group); others have found no relation. ${ }^{29}$ Studies showing an effect have been interpreted as breast feeding protecting immunologically against otitis media, but other hypothesis exist, for example, a mechanical effect of feeding position. A review $^{30}$ of the relation between breast feeding and infectious diseases generally, examined the results from six methodologically sound studies and found that, after controlling for family size, smoking, and parental education, the positive effect of breast feeding was eliminated. Our analyses contribute to that conclusion.

We conclude that the general reasons for encouraging breast feeding remain, but the precise association of middle ear disease with breast feeding remains too unclear to include in evidence-based health promotion advice concerning middle ear disease.

\section{IMPLICATIONS FOR PREVENTION AND}

MANAGEMENT

The main replicable risk factors are environmental, but it is questionable whether intervention can reduce them. In one study, ${ }^{2}$ parents were given advice to help minimise exposure of susceptible children to factors such as day care, overcrowding, and air pollution; where children had had five or more middle ear infections before 30 months, parents were no more likely to make changes in their daily family life (one or more of changes in smoking habits, working hours, housing or day care) than in a matched control group of parents. However, before a 
pessimistic conclusion is reached, a larger representative study should be conducted on a randomised basis with a maximal and well specified intervention and strong support for the advice given to reduce risk factors.

Future risk factor studies should provide control for the main expected confounders, preferably at the design stage but at least in the analysis using regression techniques as used here. Highly matched case-control studies of practicably large sample size are also called for to complement population studies; markers of middle ear disease are desirable, and better quantification of persistence, including duration and severity of the disease, but studies possessing those virtues have so far not produced radically new risk factors nor generally cumulative odds ratios greater than those observed here. ${ }^{3}$

We thank the Social Statistics Research Unit in London for supplying the documented data and Sarah Smith for the derivation of the service uptake/general health score. We are also grateful to of the service uptake/general health score. We are also
the Hearing Research Trust for financial support.

1 Tos M. Sequelae of otitis media with and without treatment. Ann Otol Rhinol Laryngol 1987;S146:18.

2 Bexell A, Rastam L, Isaccsson S-O, et al. Parents' response to middle ear infection in their children. Scand F Soc Med to middle ear in

3 Zielhuis GA, Heuvelmans-Heinen EW, Rach GH, et al. Environmental risk factors for otitis media with effusion in Environmental risk factors for otitis media with effusion in
pre-school children. Scand $\mathcal{F}$ Prim Health Care 1989;7:338 .

4 Daly K, Giebink GS, Le CT, et al. Determining risk for chronic otitis media with effusion. Pediatr Infect Dis $\mathcal{F} 1988$ 7:471-5

5 Collett JP, Burtin P, Gillet J, et al. Risk of infectious diseases in children attending different types of day-care setting. Respiration 1994;61 (suppl 1):16-19.

6 Etzel RA, Pattishall MD, Haley NJ, et al. Passive smoking and middle ear effusion among children in day care. Pediatrics 1992;90:228-32.

7 Strachan DP, Jarvis MJ, Feyerabend C. Passive smoking, salivary cotinine concentrations and middle ear effusions in 7 year old children. BMF 1989;298:1549-52.

8 Hinton AE. Passive smoking and otitis media with effusion. BMF 1992;304:53.

9 Rowe-Jones JM, Brockbank MJ. Parental smoking and persistent otitis media with effusion in children. Int $\mathcal{f}$ Pediat sistent otitis media with effusion

10 Teele DW, Klein JO, Rosner B and the Greater Boston Study Group. Epidemiology of otitis media during the first seven years of life in children in Greater Boston: A prospective, cohort study. F Infect Dis 1989;160:83-94.

11 Irander K, Borres MP, Bjorksten B. Middle ear disease in relation to atopy and nasal metachronic cells in infancy. Int f Pediatr Otorhinolaryngol 1993;26:1-9.

12 Kraemer MJ, Richardson MA, Weiss NS, et al. Risk factors for persistent middle ear effusions: otitis media, catarrh, cigarette smoke exposure and atopy. $\mathcal{F} A M A$ 1983;249: 1022-5.

13 Van Cauwenberge PB, Kluyskens PM. Some predisposing factors in otitis media with effusion. In: Lim DJ, Bluestone $\mathrm{CD}$, Klein JO, et al, eds. Recent advances in otitis media with effusion. Philadelphia: BC Decker, 1984.

14 Williamson IC, Dunleavey J, Robinson D. Risk factors for otitis media with effusion: a 1-year case-control study in 5-7 year old children. Fam Pract 1994;11:271-4.

15 Rach GH, Zielhuis GA, van den Broek P. The influence of chronic persistent otitis media with effusion on language development of 2 - to 4 -year-olds. Int $\mathcal{F}$ Pediatr Otorhinolaryngol 1988;15:253-61.

16 Pless CE, Pless IB. How well they remember - the accuracy of parent reports. Arch Pediatr Adolesc Med 1995;149:5538.

17 Daly KA, Lindgren B, Giebink GS.Validity of parental report of a child's medical history in otitis media research. Am f Epidemiol 1994;139:1116-21.

18 Kannel WB. An epidemiological perspective in hypertension problem solving. Cardiology 1994;85:71-7.

19 Blakley BW, Blakley J.E. Smoking and middle ear disease: Are they related? A review article. Otolaryngol Head Neck Surg 1995;112:441-6.

20 Butler NR, Golding J. From birth to five. Oxford: Pergamon Press, 1986.

21 Osborne AF, Morris TC. The rationale for a composite index of social class and its evaluation. Br F Sociol 1979;30: 39-60.

22 GLIM Statistical package. Oxford: The Numerical Algorithm Group, 1993.

23 Poswillo D, Alberman E. Effects of smoking on the fetus, neonate, and child. Oxford: Oxford University Press, 1992.

24 Charlton A. Children and passive smoking: a review. 7 Fam Pract 1994;38:267-77.

25 Froom J, Culpepper L. Otitis media in day-care children. A report from the international primary care network. I Fam Pract 1991;32:289-94.

26 Duncan B, Ey J, Holberg C J, et al. Exclusive breast-feeding for at least 4 months protects against otitis media. Pediatrics 1993;91:867-72.

27 Ford K, Labbok M. Breastfeeding and child health in the United States. F Biosoc Sci 1993;25:187-94.

28 Owen MJ, Badwin CD, Swank PR, et al. Relation of infant feeding poistion, cigarette smoke exposure, and group day care in the onset and duration of otitis media with effusion in the first two years of life. F Pediat 1993;123:702-11.

29 Tainio VM, Savilahti E, Salmenpera L, et al. Risk factors for infantile recurrent otitis media: atopy but not type of feeding. Pediatr Res 1988;23:509-12.

30 Bauchner H, Leventhal J, Sharpiro E. Studies of breastfeeding and infection: how good is the evidence? $f A M A 1986$; 256:887. 